\title{
Turboelectric Distributed Propulsion Engine Cycle Analysis for Hybrid-Wing-Body Aircraft
}

\author{
James L. Felder ${ }^{1}$, Hyun Dae Kim ${ }^{2}$ and Gerald V. Brown ${ }^{3}$ \\ NASA Glenn Research Center, Cleveland, Ohio, USA
}

\begin{abstract}
Meeting NASA's $\mathbf{N}+3$ goals requires a fundamental shift in approach to aircraft and engine design. Material and design improvements allow higher pressure and higher temperature core engines which improve the thermal efficiency. Propulsive efficiency, the other half of the overall efficiency equation, however, is largely determined by the fan pressure ratio (FPR). Lower FPR increases propulsive efficiency, but also dramatically reduces fan shaft speed through the combination of larger diameter fans and reduced fan tip speed limits. The result is that below an FPR of 1.5 the maximum fan shaft speed makes direct drive turbines problematic. However, it is the low pressure ratio fans that allow the improvement in propulsive efficiency which, along with improvements in thermal efficiency in the core, contributes strongly to meeting the $\mathbf{N}+3$ goals for fuel burn reduction. The lower fan exhaust velocities resulting from lower FPRs are also key to meeting the aircraft noise goals. Adding a gear box to the standard turbofan engine allows acceptable turbine speeds to be maintained. However, development of a $50,000+$ hp gearbox required by fans in a large twin engine transport aircraft presents an extreme technical challenge, therefore another approach is needed. This paper presents a propulsion system which transmits power from the turbine to the fan electrically rather than mechanically. Recent and anticipated advances in high temperature superconducting generators, motors, and power lines offer the possibility that such devices can be used to transmit turbine power in aircraft without an excessive weight penalty. Moving to such a power transmission system does more than provide better matching between fan and turbine shaft speeds. The relative ease with which electrical power can be distributed throughout the aircraft opens up numerous other possibilities for new aircraft and propulsion configurations and modes of operation. This paper discusses a number of these new possibilities. The Boeing N2 hybrid-wing-body (HWB) is used as a baseline aircraft for this study. The two pylon mounted conventional turbofans are replaced by two wing-tip mounted turboshaft engines, each driving a superconducting generator. Both generators feed a common electrical bus which distributes power to an array of superconducting motor-driven fans in a continuous nacelle centered along the trailing edge of the upper surface of the wing-body. A key finding was that traditional inlet performance methodology has to be modified when most of the air entering the inlet is boundary layer air. A very thorough and detailed propulsion/airframe integration (PAI) analysis is required at the very beginning of the design process since embedded engine inlet performance must be based on conditions at the inlet lip rather than freestream conditions. Examination of a range of fan pressure ratios yielded a minimum Thrust-specific-fuel-consumption (TSFC) at the aerodynamic design point of the vehicle $(31,000 \mathrm{ft} /$ Mach 0.8) between 1.3 and 1.35 FPR. We deduced that this was due to the higher pressure losses prior to the fan inlet as well as higher losses in the 2-D inlets and nozzles. This FPR is likely to be higher than the FPR that yields a minimum TSFC in a pylon mounted engine.
\end{abstract}

\footnotetext{
${ }^{1}$ Aerospace Engineer, DSS, 21000 Brookpark Rd, Cleveland, OH 44145

${ }^{2}$ Aerospace Engineer, RTM, 21000 Brookpark Rd, Cleveland, OH 44145

${ }^{3}$ Aerospace Engineer, RXS, 21000 Brookpark Rd, Cleveland, OH 44145.
} 


\section{Nomenclature}

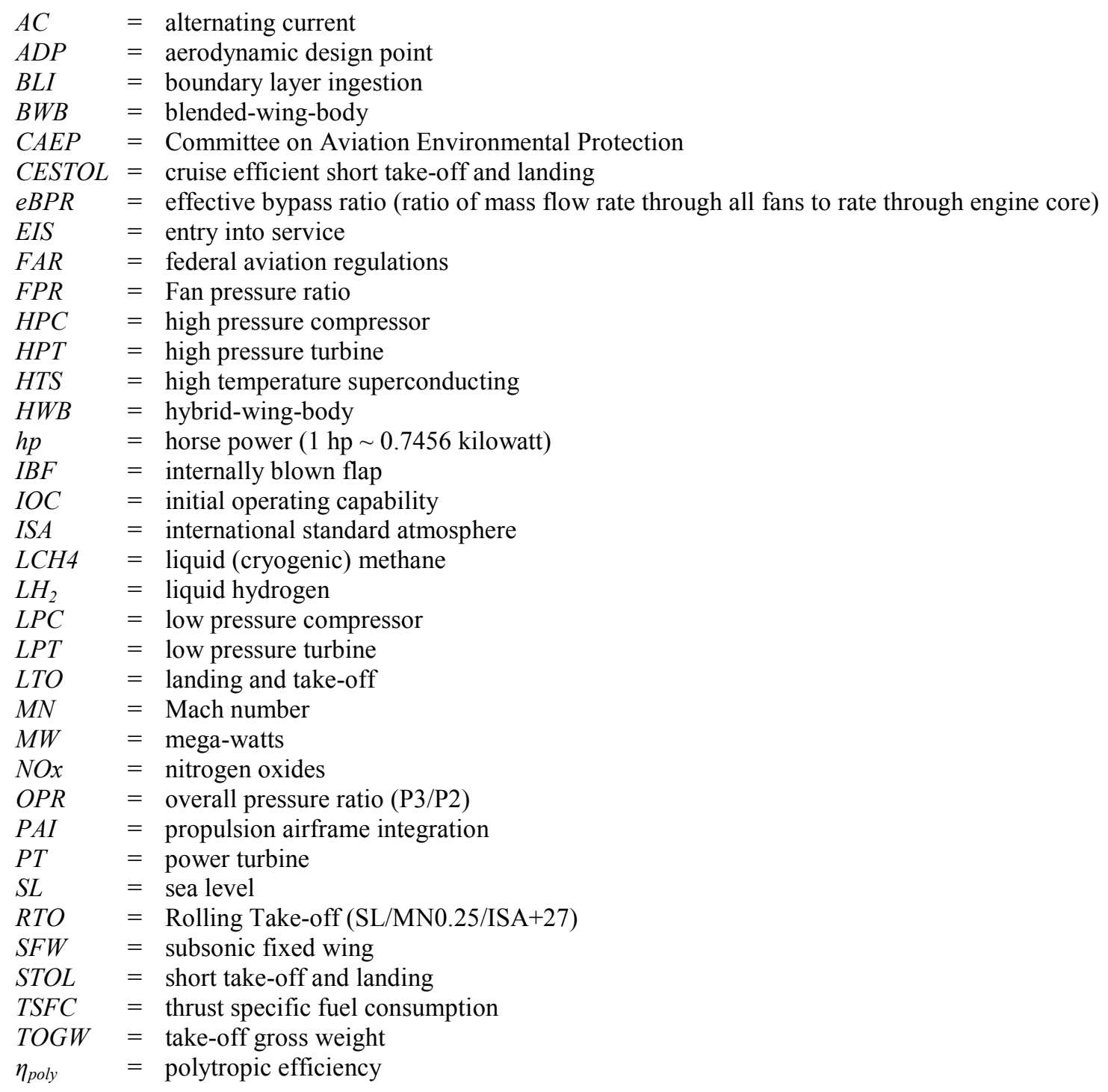




\section{Introduction}

$I$ $\mathrm{n}$ response to growing aviation demands and concerns about the environment, NASA's Subsonic Fixed Wing (SFW) project identified four "corners" of the technical trade space - noise, emissions, aircraft fuel burn, and field length - for aircraft design. Table 1 lists these technology goals for three future time frames, where $\mathrm{N}+1, \mathrm{~N}+2$, and $\mathrm{N}+3$ represent the years 2015, 2020, and 2030, respectively. Although it may not be feasible to meet all the goals for each time frame, the multi-objective studies will attempt to identify possible vehicle concepts that have the best potential to meet the combined goals.

One of the vehicle and propulsion concepts that NASA is exploring for $\mathrm{N}+2$ is a synergistic combination of a hybrid-wing-body airframe and a distributed propulsion system. A number of fixed wing aircraft using 'distributed propulsion' have been proposed and flown before, although what constitutes distributed propulsion is not clearly defined. Examples include the 1940's YB-49 flying wing aircraft with 4 completely embedded engines in each side of the wing and the 1960's Hunting H.126 jet flap research aircraft which diverted almost $60 \%$ of its thrust across its wing trailing edge to achieve

\begin{tabular}{|l|c|c|c|}
\hline $\begin{array}{c}\text { Corners of the } \\
\text { trade space }\end{array}$ & $\begin{array}{c}\mathrm{N}^{\mathrm{a}}+1 \text { (2015 EIS) } \\
\text { Generation } \\
\text { Conventional Tube } \\
\text { and Wing (relative to } \\
\text { B737/CFM56) }\end{array}$ & $\begin{array}{c}\mathrm{N}^{\mathrm{a}}+2(2020 \\
\text { IOC) } \\
\text { Generation } \\
\text { Conventional } \\
\text { Hybrid-wing- } \\
\text { body } \\
\text { (relative to } \\
\text { B777/GE90) }\end{array}$ & $\begin{array}{c}\mathrm{N}^{\mathrm{a}+3(2030-} \\
2035 \mathrm{EIS}) \\
\text { Advanced } \\
\text { Aircraft } \\
\text { Concepts }\end{array}$ \\
\hline $\begin{array}{l}\text { Noise } \\
\text { (cumulative } \\
\text { below } \\
\text { Stage 4) }\end{array}$ & $-32 \mathrm{~dB}$ & $-42 \mathrm{~dB}$ & $\begin{array}{l}55 \text { LDN at } \\
\text { average } \\
\text { airport } \\
\text { boundary }\end{array}$ \\
\hline $\begin{array}{l}\text { LTO NOx } \\
\text { Emissions } \\
\text { (below CAEP/6) }\end{array}$ & $-60 \%$ & $\begin{array}{l}\text { Better than } \\
-75 \%\end{array}$ \\
\hline $\begin{array}{l}\text { Performance: } \\
\text { Aircraft } \\
\text { Burn }\end{array}$ & $-33 \%{ }^{\mathrm{b}}$ & $-75 \%$ & $\begin{array}{l}\text { Better than } \\
-70 \%\end{array}$ \\
\hline $\begin{array}{l}\text { Performance: } \\
\text { Field Length }\end{array}$ & $-33 \%$ & $-40 \%{ }^{\mathrm{b}}$ & $\begin{array}{l}\text { Exploit } \\
\text { metroplex } \\
\text { concepts }\end{array}$ \\
\hline
\end{tabular}

a "N" represents current state-of-art aircraft as stated in parenthesis.

b An additional reduction of $10 \%$ may be possible through improved operational capability.

${ }^{\mathrm{c}}$ Concepts that enable optimal use of the airports (with shorter runway) within the metropolitan areas.

Table 1 NASA's Technology Goals for Future Subsonic Fixed Wing (SFW) Vehicles very high lift capability.

In 2006 NASA funded a one-year study that evaluated the synergistic benefits of distributed propulsion and airframe integration with respect to cruise efficiency and quiet operation of aircraft from regional airports [1,2]. The configuration for that study utilized 12 small conventional high-bypass-ratio turbofan engines, each with about 7,000 lbs $(\sim 31,000 \mathrm{~N})$ of thrust at sea level, powering a hybrid-wing-body (HWB) vehicle (Figure 1). The HWB is the main object of study to meet NASA's N+2 goals.

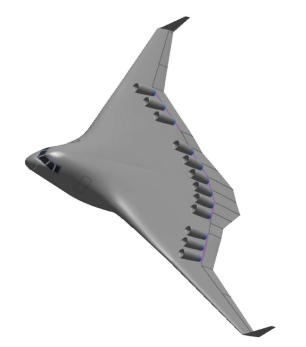

Figure 1 Cruise efficient short take-off and landing (CESTOL) vehicle configuration using 12 small conventional high bypass ratio turbofan engines
For the Silent Aircraft Initiative the Cambridge-MIT Institute (CMI) developed the SAX-40 conceptual design $[3,4]$. Boeing and NASA developed this concept further with the N2 aircraft [6]. Figure 2 shows these aircraft. The N2 is a conventional takeoff hybrid-wing-body aircraft with a 461,500 $\mathrm{lbm}$ MTOGW, 103,000 $\mathrm{lbm}$ payload and a $6,000 \mathrm{~nm}$ range. Two configurations were examined. The N2A uses two pylon mounted turbofan engines mounted on the upper rear fuselage section. The N2B replaces the two turbofan engines with three propulsion modules. Each propulsion module as shown in Figure 3 consists of

three side-by-side fans driven by a common turbine. The center fan is in line with the core and is directly driven by the fan turbine. The other two fans are on each side and are driven by right-angle gearboxes powered by the fan turbine. 

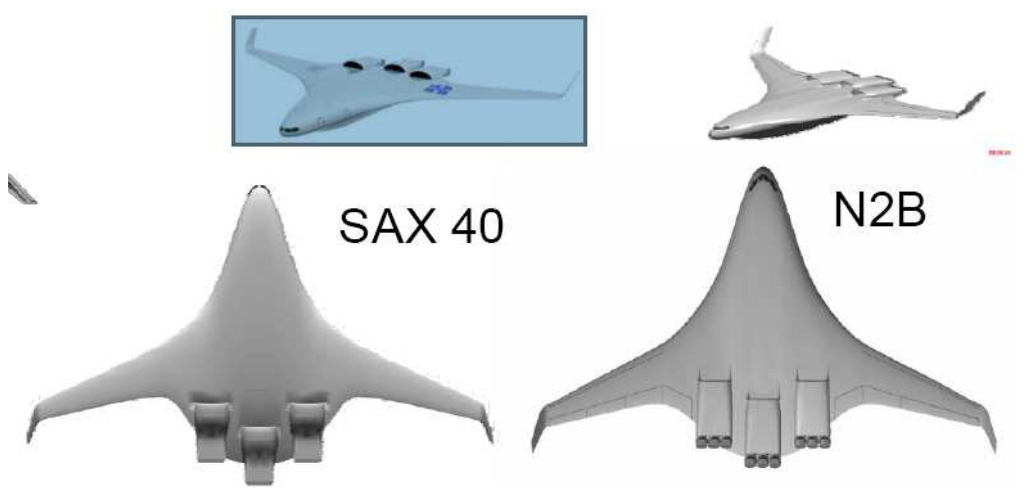

Figure 2. The CMI SAX-40 and Boeing/NASA N2A and N2B Hybrid-wing-body Aircraft Concepts

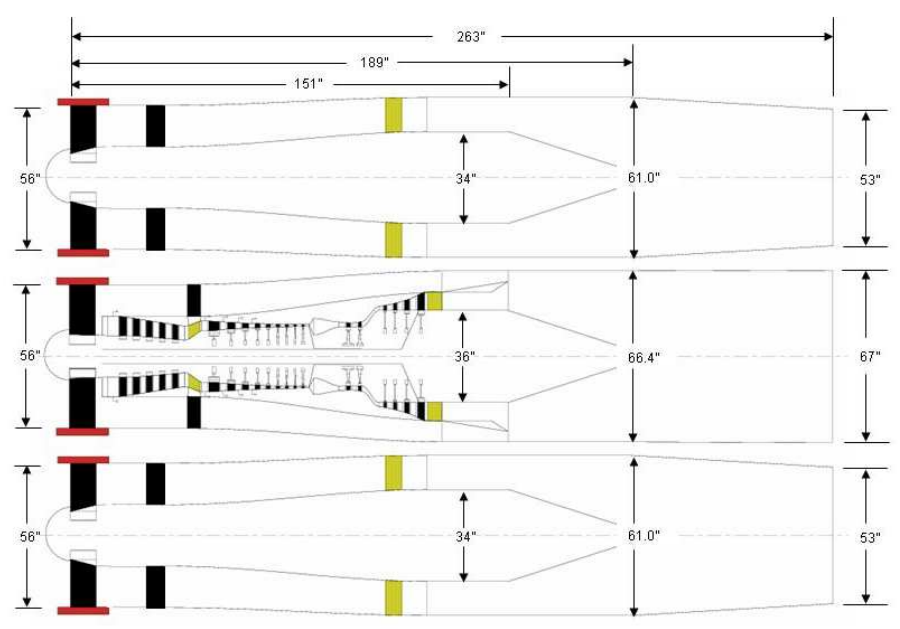

Figure 3. Boeing/NASA N2B Three-fan/Single Core Engine

To improve vehicle performance enough to meet NASA's N+3 goals, a drastic change in propulsion system is required. In a paper presented at the International Powered Lift Conference [5] written by the authors, the 12 conventional turbofan engines of the cruise efficient short take-off and landing (CESTOL) aircraft shown in Figure 1 were replaced with 16 fans driven by superconducting electric motors. The fans were housed in a continuous nacelle across the upper trailing edge of the HWB aircraft. Upper surface blowing (USB) by cool fan air of the outer fans provide powered lift that dramatically enhances STOL performance, while the inner fans substantially improve the effectiveness of the pitch effector. The power needed for these electric fans comes from two wing-tip mounted gas-turbine-driven superconducting generators, with the power distributed through superconducting electrical lines. This arrangement allows many small partially embedded fans operating in the boundary layer, while retaining the superior efficiency of large core engines operating in undisturbed air. The resulting conceptual configuration is shown in Figure 4. 


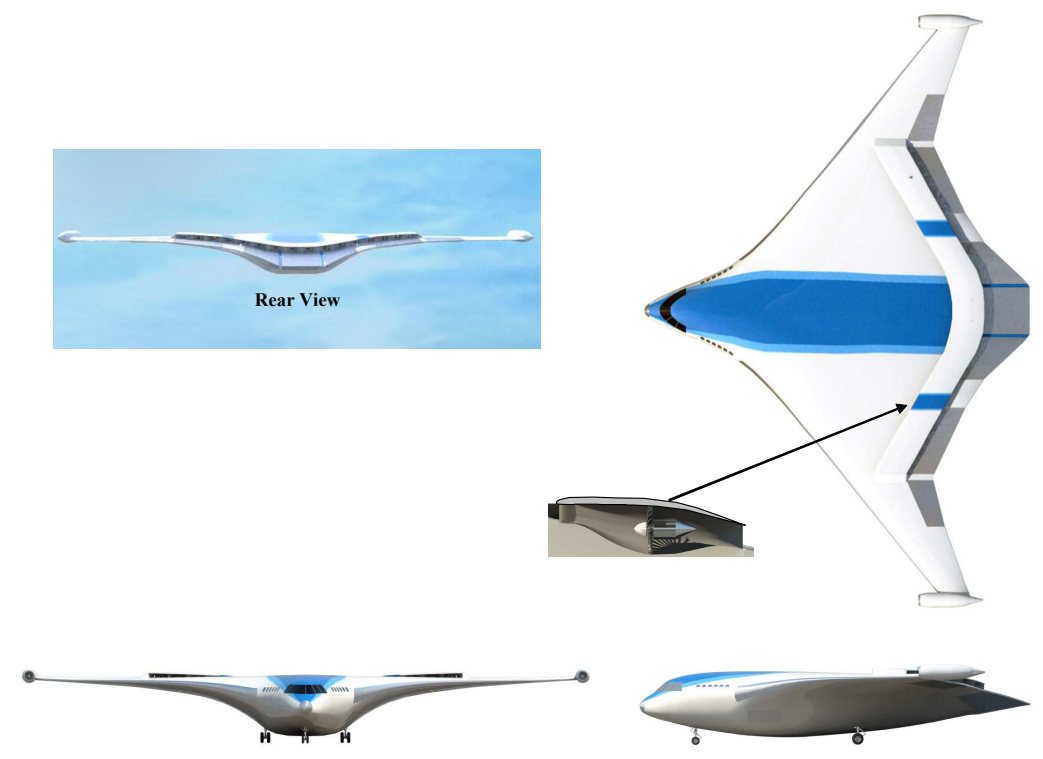

Figure 4. A notional distributed turbo-electric propulsion CESTOL vehicle concept using 16 distributed electric fans driven by superconducting motors with power provided by two wing-tip mounted turbo-electric generators

\section{N3-X Propulsion Cycle Design}

\section{A. Propulsion System Configuration}

For this study of embedded superconducting turboelectric propulsion we used the N2A airframe as our baseline. Two key N2A flight conditions were used as benchmarks in this study. They are the aerodynamic design point (ADP) at 31,000 feet, MN 0.8, ISA where the vehicle thrust requirement is 30,000 lbf, and a rolling take-off (RTO) condition at sea level, MN 0.25 , and ISA $+27{ }^{\circ} \mathrm{R}$ where the thrust requirement is $\left.108,000 \mathrm{lbf} 6\right]$.

We modified this airframe by removing the pylon mounted turbofan engines and the vertical tails. In their place is a nacelle on the upper surface at the trailing edge which contains the motor-driven fan modules. The fans are driven by electrical power generated by the wing tip mounted turbogenerators. Figure 5 shows our conceptual design We have dubbed this combination of airframe and superconducting electrical propulsion the N3-X

The propulsion system design point was set at the RTO condition, and the propulsion system was sized to provide a total vehicle thrust of 108,000 lbf with two turbogenerators and a number of fans that depends on the ADP FPR value being evaluated. Even though all power goes through a common power bus, symmetry was assumed and the propulsion system simulation model consisted of one turbogenerator and half the fans. Further, the aggregate performance of the fans was represented by a single fan module in the simulation. The simulation then produces values for aggregate performance of all fan modules as well as the total inlet, fan and nozzle areas. Post convergence calculations determined the flow areas for each individual fan module and the diameter of each fan. Future analysis will split the fan into individual fan elements in the simulation, each with its own inlet and nozzle. This will allow the span-wise difference in inlet conditions due to different fuselage length upstream of each inlet to be incorporated into the propulsion system simulation.

The fan module design values at the RTO design condition were varied to yield the desired fan pressure ratio, fan face $\mathrm{MN}$, and maximum fan tip speed at the ADP.

The ADP thrust required by the N2A aircraft was specified as $30,000 \mathrm{lbf}[6]$. We reduced this value by $7 \%$ to account for reduced system dissipations as a result of boundary layer ingestion. The 7\% value was selected as a reasonable value based on previous studies and papers. Each parametric engine design for the examined FPRs was checked to make sure that it would meet the RTO thrust requirement at a maximum combustor exit temperature, T4, 
value and the ADP thrust at a $\mathrm{T} 4$ of at least $150{ }^{\circ} \mathrm{R}$ less than the maximum value. All parametric engine designs were able to meet both conditions.

The shaft speed of the power turbine and generator are not connected to the speed of the fan in any way. Power inverters are used in the electrical distribution system that allows the frequencies of the generator and motors to be varied independently. Thus each can operate at its most advantageous rotational speed. In effect the electrical distribution system acts like a variable ratio gearbox, a degree of freedom simply not possible with a mechanical gearbox. Further electrical motors and generators can vary power for the same rotational speed, introducing another degree of freedom to the operation of both the fans and the turbogenerators.
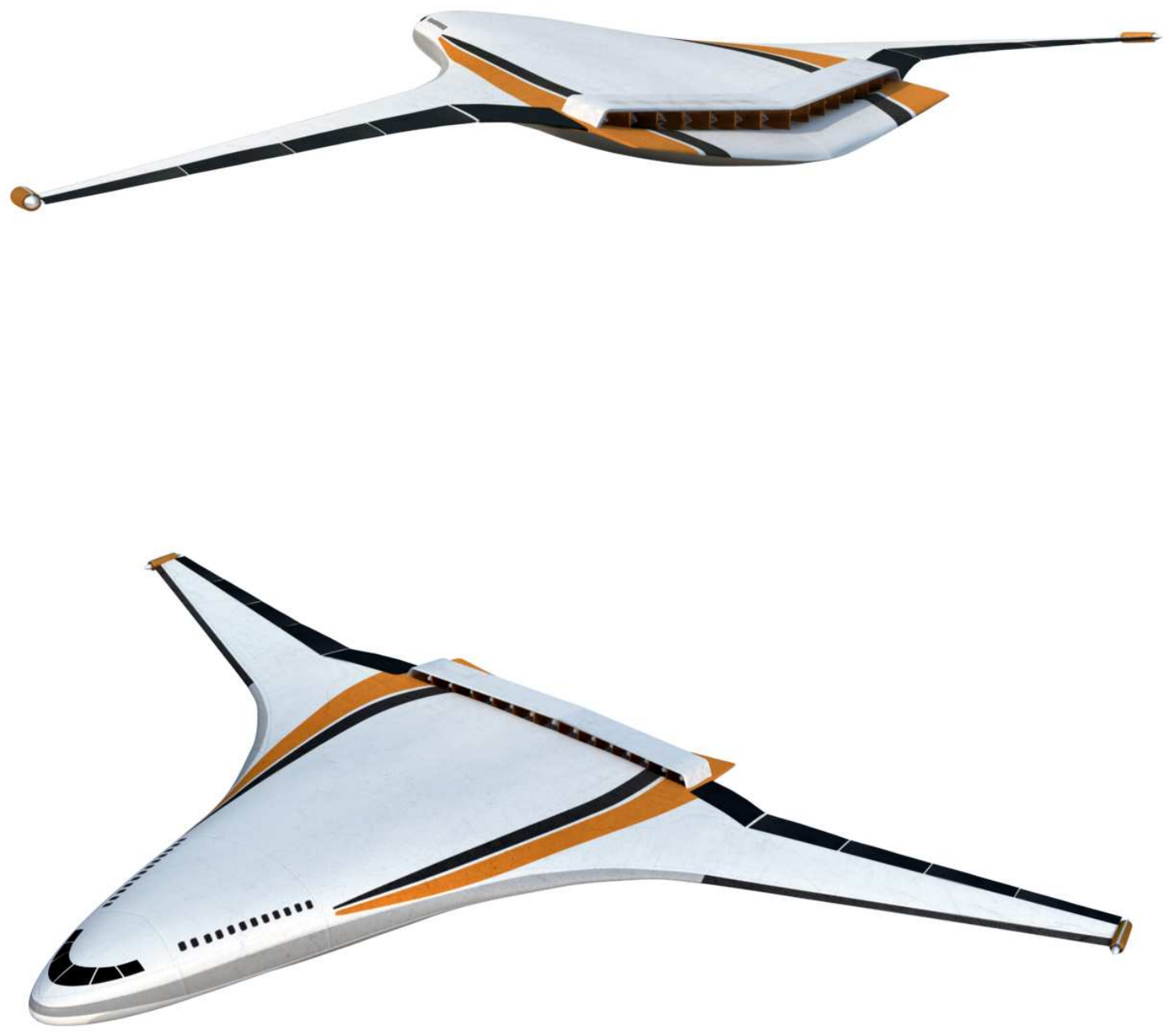

Figure 5. N3-X Concept

American Institute of Aeronautics and Astronautics

092407 


\section{B. Fan Module Configuration}

The superconducting motor-driven fan modules are arrayed across the trailing edge of the center fuselage section. To increase BLI benefits and to minimize interference drag between the fan nacelle and external flows, the fans are housed in a single box nacelle. This nacelle features a continuous high-aspect-ratio 2-D 'mail-slot' inlet and nozzle. Vertical splitters just behind the inlet lip segment the incoming flow into diffusion sections for each fan. Similar dividers segment the continuous nozzle into 2-D box nozzles for each fan. A single span-wise-continuous surface forms the top of the nacelle. The nozzles exhaust at the surface of the fuselage and at a distance from the trailing edge of at least four times the nozzle height. This provides a high degree of noise shielding to the community below and sideline noise reduction due to fan jet-to-jet shielding. We therefore removed the vertical fins from the baseline N2A configuration for the same reasons as described in reference 5. However, we did not try to take any drag reduction credit for their elimination. Without the vertical fins the distance between the inboard edges of the flap system is about 780 inches. We used this distance as the span-wise distance of the fan nacelle.

This configuration confers a number of advantages. A very important one for HWB aircraft is that the vertical center-of-thrust is much closer to the vehicle vertical center-of-gravity than the original pylon mounted turbofan, thus producing a much lower nose down pitching moment for a given thrust. Another advantage of particular relevance to the examination of very low fan pressure ratios is that the amount of additional external wetted area due to the fan nacelles over that of the bare airframe is only the wetted areas of the vertical sides of the nacelle. The upper surface of the nacelle is equal to the fuselage area covered by the nacelle. Thus the external wetted area of the aircraft with and without the propulsion system is nearly identical. As fan diameter increases due to lower fan pressure ratio the only increase in external wetted area is the extra vertical area of the fan nacelle. Any increase in the size of the top of the nacelle is offset by an equal decrease in airframe wetted area. Since the top of the fan nacelle is likely to have laminar flow over at least a portion of it, while the fuselage that is being covered is where the turbulent boundary layer is thickest, a increasing fan nacelle length might actually decrease drag.

The number of fan modules varies with FPR. As fan diameter increases as a result of lower FPRs, fewer fans will fit within the available span. The number of fans for each FPR was varied until the span was filled with a reasonable separation between fans.

The range of FPRs examined requires a variable area fan nozzle for fan stability. The continuous 2-D nozzle makes it simple to hinge the upper surface of the nozzle to change the nozzle area. A similar simple hinge would also make a variable area inlet possible if such were required. Table 2 and Table 3 give a list of the primary design parameters and values used in the cycle design of the fan module.

\section{Turbogenerator Configuration}

A wing tip location for the turbogenerator was chosen to provide wing bending moment relief while the aircraft is in flight and easier access to the turbine engine and superconducting generator at the expense of some extra downward load during landing and on the ground. Such a location also provides maximal separation from passengers or payload and other critical system in the event of an uncontained failure of the turbomachinery. Other factors such as cyro-refrigerator volume requirements and/or cryo-coolant line length limitations may mitigate in favor of locating the turbogenerator elsewhere on the vehicle.

The turbogenerator was sized to produce very little thrust of its own. Instead the turbine system was sized to leave only enough nozzle pressure ratio so that at cruise conditions the turbogenerator makes a small amount of net thrust. This provides for the maximum energy extraction to drive the fans, and minimize turbogenerator exhaust velocity with an attendant reduction in noise. The turboshaft engine

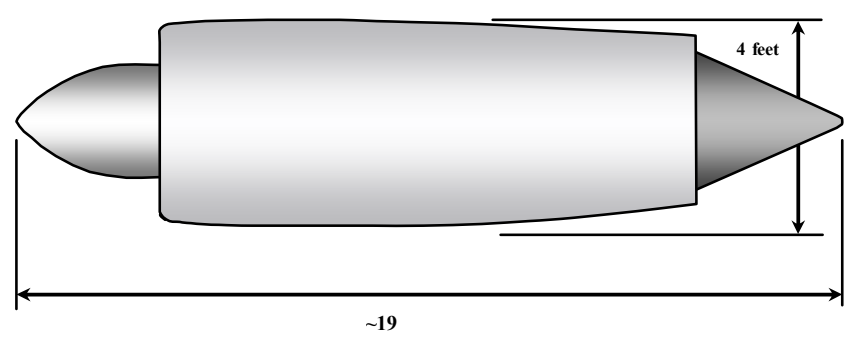

Figure 6. Estimated size and shape of the Turbogenerator consists of a two-spool gas generator and a separate power turbine driving a front mounted superconducting electrical generator. The front mounting of the generator was selected even though this configuration will require three concentric shafts. Placing the generator aft of the power turbine would have allowed the generator shaft to be in line rather than concentric with the other two shafts. However the heat leak into the cryogenically cooled superconducting generator from the turbine exhaust would have been unacceptable. The design of the compression 
system was set so that at the design conditions the compressor exit temperature (T3) is at the maximum specified temperature. This determines the overall pressure ratio (OPR). At the same time the OPR was divided between the two compressors such that there was an equal enthalpy rise across the two compressors. Table 2 give a list of the primary design parameters and values used in the cycle design of the turbogenerator.

\begin{tabular}{|c|c|}
\hline \multicolumn{2}{|r|}{ Vehicle } \\
\hline $\begin{array}{ll}\text { Thrust @ } & \text { RTO } \\
\text { (Design pt) } & \end{array}$ & $108,000 \mathrm{lbf}$ total \\
\hline Thrust@ADP & $\begin{array}{l}30,000 \mathrm{lbf} \text { bare aircraft } \\
27,900 \mathrm{lbf} \text { with BLI }\end{array}$ \\
\hline \multicolumn{2}{|r|}{ Fan Module } \\
\hline Inlet & $\begin{array}{l}\eta_{\mathrm{ram}}=0.99 @ \text { Design } \\
\eta_{\mathrm{ram}}=0.965 @ \text { ADP }\end{array}$ \\
\hline Fan & $\begin{array}{l}\eta_{\text {poly }}=0.94 \\
\text { hub/tip }=0.3 \\
\mathrm{MN}=0.62 @ \text { ADP }\end{array}$ \\
\hline Nozzle & $\begin{array}{l}\mathrm{C}_{\mathrm{v}}=0.9973 \\
\text { Variable Area } \\
\end{array}$ \\
\hline \multicolumn{2}{|r|}{ Turbogenerator } \\
\hline Inlet & $\eta_{\mathrm{ram}}=0.99$ \\
\hline LPC & $\eta_{\text {poly }}=0.93$ \\
\hline HPC & $\eta_{\text {poly }}=0.93$ \\
\hline $\begin{array}{l}\text { Total } \\
\text { Compression }\end{array}$ & $\begin{array}{l}\mathrm{T}_{3}(\max )=1350^{\circ} \mathrm{F} \\
\Delta \mathrm{h}(\mathrm{LPC})=\Delta \mathrm{h}(\mathrm{HPC})\end{array}$ \\
\hline Burner & $\begin{array}{l}\mathrm{T}_{4}(\max )=3000^{\circ} \mathrm{F} \\
\Delta \mathrm{P}=4.5 \% \\
\mathrm{LHV}=18580 \mathrm{BTU} / \mathrm{lbm}\end{array}$ \\
\hline HPT & $\eta_{\text {adiabatic }}=0.91$ \\
\hline LPT & $\eta_{\text {adiabatic }}=0.91$ \\
\hline $\mathrm{PT}$ & $\eta_{\text {adiabatic }}=0.94$ \\
\hline Nozzle & $\begin{array}{l}\mathrm{C}_{\mathrm{v}}=0.9973 \\
\mathrm{PR}=1.15 @ \text { design pt. }\end{array}$ \\
\hline
\end{tabular}

Table 2. Design Parameter Values @ Sea Level / MN 0.25 / ISA+27 and Key Off-Design Performance Goals@31k / MN0.8 / ISA ADP

\begin{tabular}{|r|r|r|r|r|r|r|}
\hline FPR & 1.25 & 1.30 & 1.35 & 1.40 & 1.45 & 1.50 \\
\hline Tip Speed Limit (ft/sec) & 890 & 967 & 1043 & 1120 & 1197 & 1273 \\
\hline
\end{tabular}

Table 3. Fan Tip Speed Limit as a Function of Fan Pressure Ratio 


\section{Propulsion System Results}

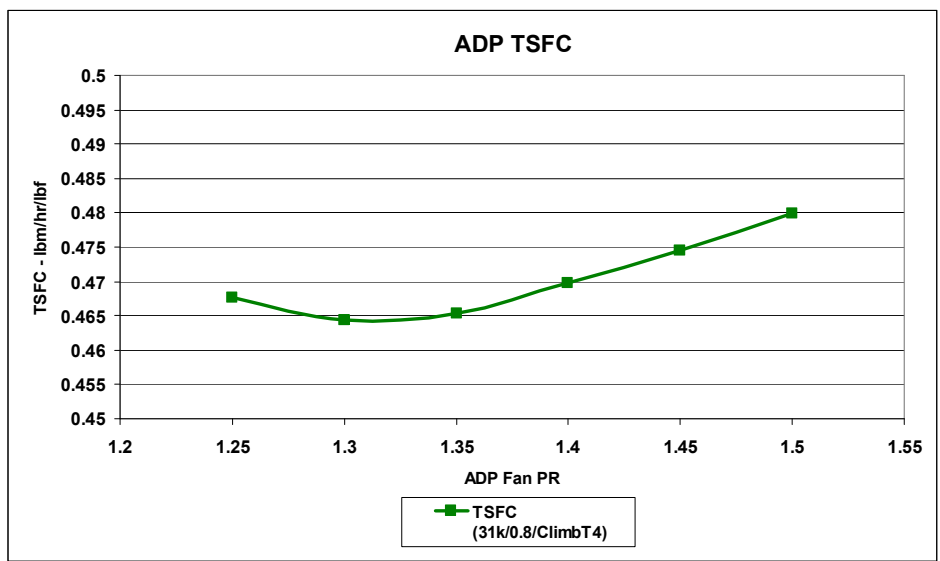

Figure 7. N3-X ADP TFSC Vs. FPR

\begin{tabular}{|c|c|c|c|}
\hline & $\begin{array}{c}\text { RTO } \\
\text { (design pt) }\end{array}$ & $\begin{array}{c}\text { SLS ISA } \\
\mathrm{T} / \mathrm{O}\end{array}$ & ADP \\
\hline Fn (lbf) & 54,000 & 88640 & 13950 \\
\hline TSFC (lbm/hr/lbf) & 0.2781 & 0.1935 & 0.4685 \\
\hline eBPR & 20.4 & 19.0 & 19.2 \\
\hline Generator (SHP/MW) & $\begin{array}{r}53,900 / \\
40.2\end{array}$ & $\begin{array}{r}62,200 / \\
46.4\end{array}$ & $\begin{array}{r}26,000 / \\
19.4\end{array}$ \\
\hline Motor (SHP/MW) & $\begin{array}{r}7,700 / \\
5.74 \\
\end{array}$ & $\begin{array}{r}8,886 / \\
6.63 \\
\end{array}$ & $\begin{array}{r}3714 / \\
2.77 \\
\end{array}$ \\
\hline Wfan-total (lbm/sec) & 3535 & 3697 & 1676 \\
\hline Fan PR & 1.287 & 1.346 & 1.35 \\
\hline Number of Fans & 7 & 7 & 7 \\
\hline Fan diameter (in) & 50.6 & 50.6 & 50.6 \\
\hline Fan Nmech (RPM) & 4829 & 5001 & 4727 \\
\hline $\begin{array}{r}\text { Inlet Height } \\
\text { ( in) } \\
\end{array}$ & 30.9 & 30.9 & 30.9 \\
\hline Fan Nozzle MN & 0.655 & 0.647 & 1.0 \\
\hline Fan Nozzle Ath $\left(\mathrm{in}^{2}\right)$ & 9397 & 9721 & 8518 \\
\hline Fan Nozzle V (ft/sec) & 751 & 724 & 1003 \\
\hline Turbogen OPR & 57.08 & 66.9 & 64.7 \\
\hline $\mathrm{T} 3\left({ }^{\circ} \mathrm{R}\right)$ & 1809 & 1777 & 1587 \\
\hline $\mathrm{T} 4\left({ }^{\circ} \mathrm{R}\right)$ & 3459 & 3459 & 3083 \\
\hline Turbogen Nozzle PR & 1.15 & 1.19 & 1.39 \\
\hline Turbogen Nozzle MN & 0.460 & 0.510 & 0.707 \\
\hline $\begin{array}{r}\text { Turbogen Nozzle V } \\
(\mathrm{ft} / \mathrm{sec})\end{array}$ & 808 & 884 & 1100 \\
\hline
\end{tabular}

Table 4. FPR 1.35 Cycle Results
A range of fan pressure ratios was examined to determine the impact of varying this parameter on performance of the N3-X. As would be expected, the effective bypass ratio increased with decreasing FPR, and the design point TSFC decreased with decreasing FPR. At the design condition decreasing FPR decreased TSFC for all FPR values examined. However, at the ADP the TSFC did not show a continuous decrease as FPR decreased. Instead the curve reached a minimum at an FPR between 1.35 and 1.30 (see Figure 7). This is due to the total pressure losses in the boundary layer ingested by the fan inlet at this flight condition which are not seen at the design point. As FPR declines a larger fraction of the total pressure rise of the fan goes to offsetting the boundary layer pressure losses. As a result more fan airflow is needed to produce the required ADP thrust than would be the case where the inlet receives undisturbed freestream air. Eventually improvements in propulsive efficiency due to reduced FPR are negated by the increased generator power required to drive the proportionately larger fans and the TSFC begins to increase.

A conventional single fan turbofan in a podded installation would see a similar effect. However, it would be the result of decreasing FPR increasing fan diameter and hence increasing the external wetted area of the nacelle. The extra nacelle drag increasingly negates the propulsive efficiency gains achieved by reducing the FPR. Thus at some point the podded turbofan installed TSFC Vs FPR curve would also reach a minimum.

American Institute of Aeronautics and Astronautics 092407 
However, the higher losses for the embedded installation compared to a pylon mount with a pitot inlet means that the bottom of the TSFC curve for embedded engines is likely to be at a higher FPR than for a podded, pylon mounted engine.

\begin{tabular}{|r|c|c|}
\hline & N2B & N3-X \\
\hline SLS Fn (lbf) & 147180 & 177278 \\
\hline SLS TSFC (lbm/hr/lbf) & 0.288 & 0.1935 \\
\hline RTO Fn (lbf) & 108000 & 108000 \\
\hline RTO TSFC (lbm/hr/lbf) & 0.398 & 0.278 \\
\hline RTO eBPR & 11.7 & 20.4 \\
\hline ADP Fn (lbf) & 30000 & 29700 \\
\hline ADP TSFC (lbm/hr/lbf) & 0.564 & 0.4685 \\
\hline ADP eBPR & 11.3 & 19.2 \\
\hline
\end{tabular}

Table 5. Comparison of N2B and N3-X Embedded Propulsion
We selected a fan pressure ratio of 1.35 for additional analysis. We did not select an FPR of 1.3, which is closer to the minimum because a lower FPR results in a larger fan. While a larger fan does not increase external wetted area as it does in a podded engine, it does cause the axial station of the inlet to move forward if the nozzle throat axial station remains constant and the $\mathrm{L} / \mathrm{D}$ of the inlet and nozzle are kept constant. The further towards the max thickness portion of the fuselage the less advantageous are the local flow conditions. Thus a 1.35 FPR yields an 8 inch smaller fan, and assuming a $1.5 \mathrm{~L} / \mathrm{D}$ for both the inlet and nozzle, a 24 inch shorter fan nacelle compared to the results for a 1.30 FPR for very little cost in specific fuel consumption.

\section{E. Propulsion Airframe Integration}

Although the vehicle described here may benefit greatly from the propulsion airframe integration as described before, it also presents challenges that were not traditionally considered in large transport design, mainly complete aerodynamic and structural integration of inlets and nozzle with airframe. By embedding the propulsion system within the airframe, the fan inlet flow field at the lip station does not experience undisturbed free stream flow as in a conventional transport but rather sees upper airframe surface boundary layer flow plus the airframe inviscid flow which could be quite different from the free stream condition.

To match the inlet mass flow rate and inlet ram drag entering the fan face at the vehicle ADP condition and to account for total pressure loss due to boundary layer build-up along airframe surface at the inlet lip location, a 1st order approximation

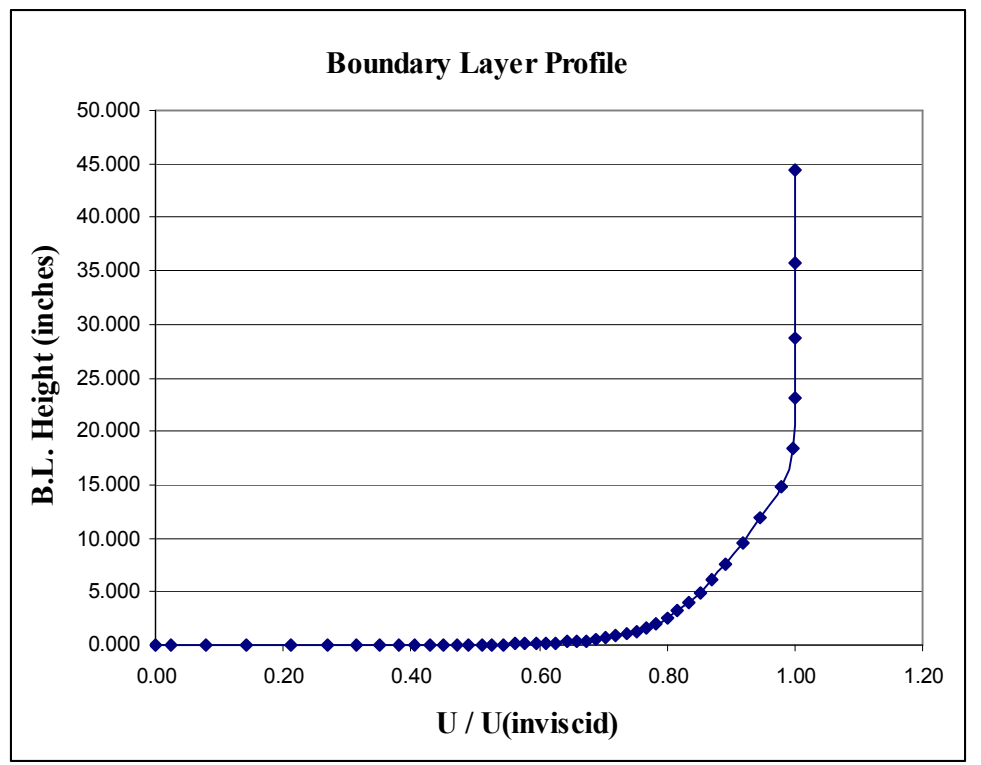

Figure 8. Assumed incoming boundary layer (B.L.) flow profile at inlet lip location with boundary layer height of $\delta \sim 18$ inches and displacement thickness of $\delta^{*} \sim 2.6$ inches

of the boundary layer profile was obtained using simple flat plate equivalent of upper airframe surface by matching assumed total pressure loss of N2A configuration and mass flow rate entering the current N3-X inlet. Figure 8 shows the flat plate boundary layer profile approaching 30.9 inches high inlet with total pressure loss of $4.3 \%$. At the 
vehicle ADP, therefore, the following inlet lip condition was calculated and compared to the values used for propulsor or fan performance study.

Simulated flat plate flow parameters at the fan inlet lip location:

Inlet height $=30.9 \mathrm{in}$.
"mass averaged" Mach number $=0.801$
"mass averaged" velocity $=787.4 \mathrm{ft} . / \mathrm{s}$
"mass averaged" temperature $=408 \mathrm{oR}$
Mass flow rate per fan $=239.4 \mathrm{lbm} / \mathrm{sec}$
Inlet ram drag per fan $=5859 \mathrm{lbf}$
Inlet lip $\mathrm{Pt} /$ Freestream $\mathrm{Pt}=0.957$
Fan face $\mathrm{Pt} /$ Inlet lip $\mathrm{Pt}=0.985$
Fan face $\mathrm{Pt} /$ Freestream $\mathrm{Pt}=0.943$

Values obtained from engine cycle analysis at the fan inlet lip location:

Inlet height $=28.3 \mathrm{in}$.

Mass flow rate per fan $=239.4 \mathrm{lbm} / \mathrm{sec}$

Inlet ram drag per fan $=5894 \mathrm{lbf}$

Inlet lip Pt / Freestream Pt $=0.9797$

Fan face Pt / Inlet lip Pt $=0.985$

Fan face $\mathrm{Pt} /$ Freestream $\mathrm{Pt}=0.965$

Thus using freestream velocity overestimates the ram drag by $35 \mathrm{lbf}$ per fan or $490 \mathrm{lbf}$ for the entire vehicle with 14 fans. This difference in ram drag represents $490 / 27900$ or $1.8 \%$ of the net thrust.

At the same time, the 0.965 used for inlet ram recovery used for the system performance calculation underestimated the total pressure loss from freestream to fan face. Rerunning the propulsion system performance study with a lower 0.943 freestream to fan face pressure ratio may result in generally higher TSFC values and a higher optimum FPR.

The importance of these results aren't the actual differences. The importance is that it illustrates the highly coupled nature of airframe and propulsion analysis for embedded propulsion systems, especially those where a considerable fraction of the propulsion inlet flow is boundary layer air. Uninstalled performance has little meaning in an embedded system and independent and largely autonomous analysis of the airframe drag and propulsion system thrust for these types of systems is unlikely to yield accurate results.

What is needed is an integrated analysis from as early in the conceptual design process as possible where actual, or at least representative, geometries are used to determine the flow conditions at the inlet physical lip. It is also highly recommended that the fluid flow profiles from the lip be carried on through the physical inlet to explicitly calculate the fan face conditions. A similar type of analysis is required for the fan nozzle exhaust since it too does not see undisturbed ambient conditions at the nozzle throat. The results of a more detailed analysis would give a much better estimate of the fuel flow required to propel the given vehicle at a given altitude and Mach number, and thus give a much clearer basis for comparison to other propulsion configurations.

\section{Superconducting Electric Drive System}

\section{A. Superconducting Generators, Motors and Transmission Lines}

The heart of this propulsion concept are the generators, motors, cables and power electronics necessary to transmit shaft power from the turbogenerators to the fan shafts of the individual fans. We feel that for large transport aircraft it will be necessary to use superconducting motors and generators rather than conventional motors and generators in the aircraft propulsion system to reduce the weight fraction of the propulsion system. Cryogenic, though not superconducting, inverters will be required as well. Conventional electric generators and motors and inverters are far too heavy to be used on a large transport air vehicle [7].

The use of gas-turbine-driven generators to supply electric power to motor-driven propulsive fans adds considerable flexibility to the propulsion and vehicle architecture. As noted above, the electric components function as a gear box allowing the turbine engines to run at high speed, independent of the fan-shaft speeds. Beyond functioning as a simple gearbox, the electric components can function as a continuously-variable-ratio gear box with the addition of a solid state power inverter. This would permit the turbogenerator power turbine and fan shaft speed 
to vary independently to yield best performance. Higher part-load efficiency can thereby be achieved. Figure 9 illustrates the components of a turboelectric propulsion system, including the power inverters

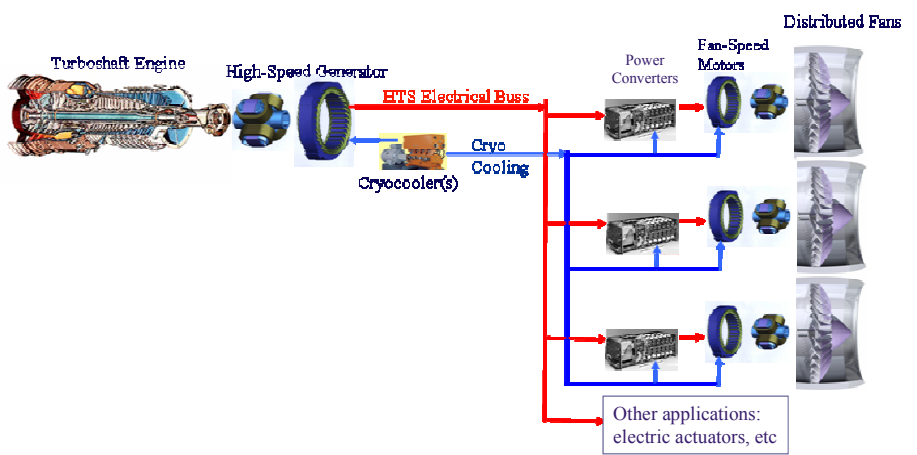

Figure 9. Components in a turboelectric propulsion system, schematically illustrated (not to scale). Motor and generator rotors and stators are axially displaced for clarity
Superconducting materials lose all their electrical resistance below a "critical" temperature and can carry high current in small wires or tapes, leading to light, compact, very efficient motors and generators. The operating temperature required for superconducting windings is somewhere between $20 \mathrm{~K}$, (the normal boiling point of liquid hydrogen) and $65 \mathrm{~K}$ (somewhat below the normal boiling point of liquid nitrogen). The state-of-the-art of cryogenic and superconducting motors and generators is reviewed in Refs. [8-10]. Machines as large as $35 \mathrm{MW}$ output[11] and as fast as $15,000 \mathrm{rpm}$ have been tested or designed. The higher performance machines are intended for military applications, but

prototypes for commercial machines are beginning to appear. High temperature superconducting (HTS) machines for aircraft propulsion have previously been discussed, primarily with "tube-and-wing" aircraft in mind [7,12].

For turboelectric aircraft propulsion, motors and generators with HTS windings on both the rotors and the stators are envisioned. In most state-of-the-art machines that are called superconducting today, only the rotor windings are superconducting. The stator windings, which are the high-power windings where most of the losses occur, are made of copper and operate at room temperature. As of this writing, only a few small experimental machines have been made with superconducting stators. The reason is that, whereas the rotor carries direct current and dissipates little power, the stator carries alternating current $(\mathrm{AC})$ and has losses that depend on the fineness of the filaments in the superconducting composite wire in the winding. Reducing those losses requires some technology development. It appears reasonable that the AC losses in a superconducting stator can be reduced to less than $0.1 \%$ of the machine's output power, with a developmental goal as low as $0.01 \%$. For the purposes of calculating the cooling required, we have assumed a power loss of $0.03 \%$ total for the entire superconducting portion of the electrical system.

The electric power would be carried from the generators to the motors by HTS transmission lines. Such lines are presently being tested in the electric grids of congested urban areas. They can carry hundreds of megawatts of power with less than $10 \mathrm{~kg} / \mathrm{m}$ of mass and only a few W/m of loss [13].

\section{B. Refrigeration Options}

The low temperatures required for the electrical components can be viewed as analogous to the lubrication required for a gear box. Both are required to remove waste heat from the power transferring components. In the electrical case this removal might be achieved in a number of different ways depending on the aircraft fuel type.

- Fully Jet-fueled: With jet-fueled aircraft, cryogenic refrigerators, or "cryo-coolers", must be used. They may be major components, depending on the efficiencies and on the weight per input power of the refrigerator. These cryo-coolers will be required to reject heat to ambient conditions. As discussed below, reasonable technology developments are required to make the refrigeration system manageable.

- Fully liquid hydrogen fueled: If future aircraft are liquid hydrogen fueled, fuel latent and sensible heat capacity can cool the electrical components before being burned in the turbine engines. The boiling point of liquid hydrogen at or near atmospheric pressure is sufficiently low to cool the superconductors directly thus eliminating the need for cryo-coolers entirely. In a fully hydrogen fueled aircraft sufficient cooling capacity may be available to enable normal conducting pure-metal stators. Operating at cryogenic temperatures the losses in the normal conducting stators, while not at superconduction levels, are very low. An all hydrogen fueled vehicle would require tanks 4 times the volume of those required for jet fuel with the same total energy, yet the total hydrogen weight would be $36 \%$ of an energy equivalent amount of jet fuel.

- Fully liquid methane fueled: Liquid methane is not cold enough to cool the superconductors directly. However it does provide a heat sink for the cryo-coolers that is only $120 \mathrm{~K}$ as opposed to as high as $325 \mathrm{~K}$ ambient temperature for a hot day condition. The liquid methane is, however, cold enough to cool the power inverters directly. Thus the cyro-coolers would only have to reject the heat due to losses in the superconducting components and only from $40 \mathrm{~K}$ to $112 \mathrm{~K}$. The result is that the cryo-coolers for a liquid methane system would 
be much smaller and lighter than required for a jet fueled aircraft. An all methane fueled vehicle would require tanks about $64 \%$ larger than for jet fuel of the same total energy. The lower density of liquid methane means that the total methane weight would be $86 \%$ of an energy equivalent amount of jet fuel.

- Liquid hydrogen only sufficient for cooling: If the losses in the superconducting components are $0.03 \%$ of the total power, then only $4 \%$ of the hydrogen flow rate of a fully hydrogen fueled aircraft is required for superconducting cooling. Cooling the superconductors requires that only the latent heat of the hydrogen be used so as to keep the temperature at the normal boiling point. The losses in the power inverters is assumed to be $0.2 \%$ of the total transmitted power. The power inverters do not need to be cooled below about $120 \mathrm{k}$. Thus the sensible heat capacity of the hydrogen used to cool the superconductors can be used to cool the power inverters. The total heat capacity of hydrogen between $20 \mathrm{~K}$ and $120 \mathrm{~K}$ is $1083 \mathrm{~J} / \mathrm{g}$. This is more than twice the latent heat capacity of $452 \mathrm{~J} / \mathrm{g}$. Thus considerable cooling capacity remains in the hydrogen after it has changed phase cooling the superconductors. However, the $4 \%$ superconductor coolant is not sufficient to absorb the $0.2 \%$ loss in the power inverters. An additional 5\% is required, for a total of $9 \%$ of the hydrogen mass flow of a fully hydrogen fueled engine. Thus it is possible to carry liquid hydrogen sufficient to provide cooling and $9 \%$ of the fuel energy required by the turbogenerators. The remainder of the fuel needed for turbogenerators can be carried as jet-fuel. Due to the much lower density of hydrogen, which is not fully offset by the higher heating value, the liquid hydrogen tanks would be about $40 \%$ of the volume of that required by the jet fuel. The energy of the hydrogen, however, reduces the volume of jet fuel required by $9 \%$, resulting in a total fuel tank volume increase of $32 \%$ compared to an all jet-fuel aircraft.

- Liquid methane only sufficient for cooling: If the losses in the superconducting components were $0.03 \%$, then assuming a $40 \mathrm{~K}$ superconducting operating temperature, a $120 \mathrm{~K}$ heat sink in the liquid methane $(112 \mathrm{~K}+8 \mathrm{~K}$ delta $\mathrm{T}$ ), and a $30 \%$ efficient Carnot refrigeration cycle, then the total cooling requirements including losses in the cryo-coolers is $0.03 \%+0.17 \%=0.2 \%$ of the total power for the low temperature cooling. The power inverters can be cooled directly with liquid methane. At liquid methane temperatures the power inverters lose an additional $0.2 \%$ of the total power, for a total power loss of $0.4 \%$. Given this loss level, the methane flow rate required for cooling is approximately $17 \%$ of that required to fully power the aircraft with methane. Thus is it possible to carry liquid methane sufficient to provide cooling and about $17 \%$ of the fuel energy required by the turbogenerators. The remainder of the fuel needed for turbogenerators can be carried as jet-fuel. Methane has about half the density of jet fuel and slightly higher heating value. The result is that the methane tanks would have a volume about $34 \%$ of the volume of the jet fuel tanks. As with hydrogen, the methane coolant displaces $17 \%$ of the jet fuel that would otherwise be required. The net increase in total fuel tank volume is therefore only $17 \%$.

One note about using cryogenic fuels for cooling; for best cooling performance the pressure of the cryogenic liquid should be at or slightly higher than one atmosphere to provide maximum energy absorption during phase change. Thus these systems would not be able to pressurize the coolant to turbogenerator burner pressure with energy efficient and compact pumps while still a liquid. While these systems may reduce or eliminate the weight and power associated with cryo-coolers, they will require gas compressors to raise hydrogen or methane pressure to burner level. Only a full system analysis will be able to determine if the power and weight of these compressors plus the extra weight of the cryogenic tanks and lines is less than the cryo-cooler weight eliminated by the use of a cryogenic fuel as coolant.

The weights and efficiencies of the electrical components of a turboelectric propulsion system will depend strongly on the level of technology development over the next 20 years or so (especially with respect to cryogenic refrigerators, and AC tolerant superconductors, and cryogenic inverters). While there is reasonable basis to expect that the assumed technology development can be achieved, it is by no means assured. Inadequate developments of light-weight cryogenic refrigerators would make tanked LH2 the preferred cooling option. If superconductors with sufficient AC tolerance are not developed, then turboelectric propulsion could still be an option on fully LH2 -fueled aircraft. 


\section{Preliminary Weight, Efficiency and Performance Estimates}

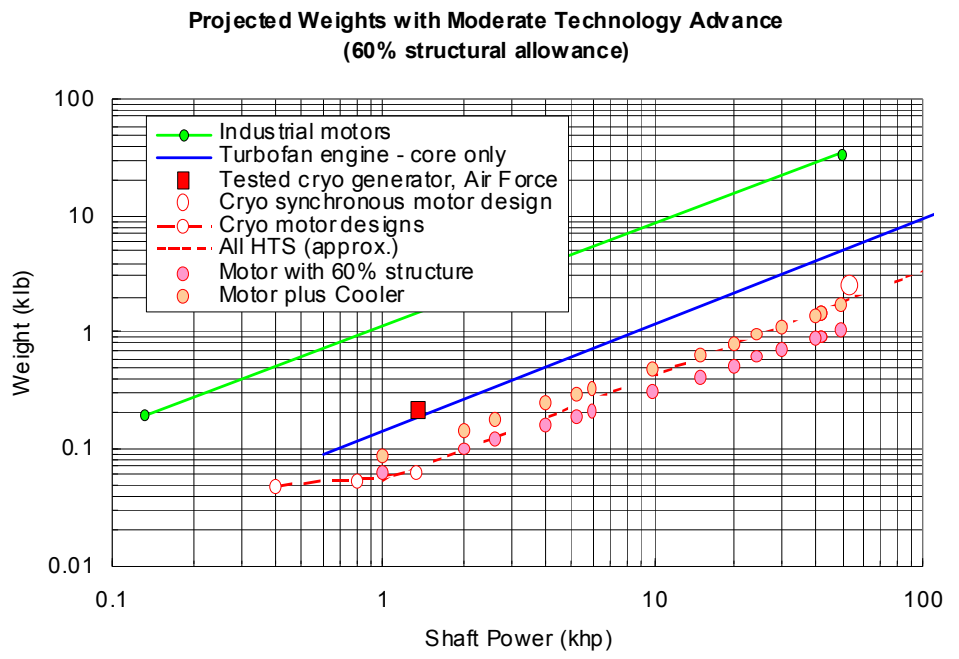

Figure 10. Weights of turbine engine cores and various types of motors and generators as functions of power. Assumed cryorefrigerator mass is $3 \mathrm{~kg} / \mathrm{kW}$-input and superconductor characteristic dimension for alternating current loss computation is $12 \mu \mathrm{m}$

In spite of uncertainty of the future level of refrigerator and $\mathrm{AC}$ superconductor technology, we present some weight and efficiency estimates that are based on the level of development that we expect for all-superconducting generators and motors. Weights as a function of power, based on electromagnetic and loss analyses from Refs. [14-16] and structural weight estimates, are shown in Figure 10. Optimization was performed to minimize motor (or generator) weight plus refrigerator weight. The refrigerator, with our assumptions, weighs $\sim 70 \%$ as much as the motor or generator that it cools. Efficiencies, including the refrigerator power, are at least $99.4 \%$. It is seen from Figure 10 that the expected weight of a motor or generator with its cooler is considerably less than the weight of a turbine engine core for equal power.

Weight and efficiency comparisons made in Table 6 are for the cooling option where the aircraft is completely fueled by jet fuel and all heat removal from the electrical system is done by refrigeration rejecting heat to ambient temperature and for the option where liquid hydrogen is used for both superconductor cooling and for power inverter cooling. Liquid hydrogen cooling does not require any active cooling and thus the weight estimates do not include refrigeration weight. The weigh estimate for liquid hydrogen cooling would apply to both an entirely hydrogen fueled aircraft and one where only sufficient hydrogen was carried to provide cooling. It is anticipated that the electrical system weights for methane cooling would lie between the two estimates and would be closer to the hydrogen cooled weights since active refrigeration is required only to remove the $0.03 \%$ estimated loss in the superconducting portions of the system. Further the refrigeration system would reject heat into the liquid methane rather than to ambient, further reducing the weight of the refrigeration system.

A fair comparison of the weights of the turboelectric systems with the different cooling options is to compare the total propulsion system weight, including any fuel tank weight beyond what is already a structural part of the aircraft, plus the fuel weight required to complete a given mission.

Comparisons of the weights of any of the turboelectric systems to other types of propulsion systems should be made on the basis of the total of the propulsion system weight, tank weight and fuel weight for a given mission. However, there is some validity to comparing the weights of the electrical portions of a turboelectric system to the gearbox weight in a geared turbofan engine, since both are additions to the basic turbofan components. 


\begin{tabular}{|c|c|c|c|}
\hline $\begin{array}{l}\text { Propulsion } \\
\text { System }\end{array}$ & Components & Weight, lbs (kg) & Efficiency, \% \\
\hline \multirow{4}{*}{$\begin{array}{l}\text { Turboelectric } \\
\text { distributed } \\
\text { fans } \\
\text { (refrigerated) }\end{array}$} & $\begin{array}{lr}2-53,000 & \mathrm{hp} \text { electric } \\
\text { generators } & \text { (including } \\
\text { refrigerators) } & \end{array}$ & $3,600(1,600)$ & 99.7 \\
\hline & $\begin{array}{l}2-53,000 \mathrm{hp} \text { inverters } \\
\text { (including refrigerators) }\end{array}$ & $10,600(4,900)$ & 98.8 \\
\hline & $\begin{array}{lr}14-7,700 & \mathrm{hp} \text { electric } \\
\text { motors } & \text { (including } \\
\text { refrigerators) } & \end{array}$ & $6,700(3,100)$ & 99.5 \\
\hline & $\begin{array}{l}\text { Total Electrical System } \\
\text { Weight }\end{array}$ & $20,900(9480)$ & 98.0 \\
\hline \multirow{4}{*}{$\begin{array}{l}\text { Turboelectric } \\
\text { distributed } \\
\text { fans }\left(\mathrm{LH}_{2}\right. \\
\text { cooled })\end{array}$} & $\begin{array}{l}2-53,000 \text { hp electric } \\
\text { generators }\left(\mathrm{LH}_{2} \text { cooled }\right)\end{array}$ & $2,300(1,100)$ & $99.9+$ \\
\hline & $\begin{array}{l}2-53,000 \text { hp inverters }\left(\mathrm{LH}_{2}\right. \\
\text { cooled) }\end{array}$ & $5,300(2,400)$ & 99.8 \\
\hline & $\begin{array}{l}14-7,700 \mathrm{hp} \text { electric } \\
\text { motors }\left(\mathrm{LH}_{2} \text { cooled }\right)\end{array}$ & $4,600(2100)$ & $99.9+$ \\
\hline & $\begin{array}{l}\text { Total Electrical System } \\
\text { Weight }\end{array}$ & $12,200(5533)$ & 99.8 \\
\hline
\end{tabular}

Table 6. Estimated Electrical System Weights and Efficiencies

\section{Advantages of Turboelectric Propulsion}

Although a distributed propulsion concept, with a small number of turboelectric generators driving numerous electric fans, could be applied to other vehicle architectures (e.g. conventional tube and wing aircraft), the concept is perhaps most naturally applied to a blended-wing-body aircraft. Nevertheless, the following are identified as possible advantages of using a turboelectric drive system on an arbitrary platform:

- Decoupling of the propulsive device from the power producing device: This is the major departure from the current state-of-art aircraft vehicle/engine design, possibly enabling unprecedented performance and design flexibility of the air vehicles. The turbine-engine-driven generators and the electric-motor-driven fans can be located at their optimum locations in the aircraft to maximize total vehicle performance and operation.

- High fuel efficiency due to high effective engine bypass ratio (eBPR): eBPR is defined as the ratio of mass flow through all fans to the mass flow through the turbogenerators.

- Integration of large fan areas into the aircraft: Multiple smaller fans area are easier to integrate into an aircraft than a single large diameter fan of equal area.

- Effect of a variable ratio gearbox: The speed of the power turbine shaft in the turbine engine is independent of the fan shaft speed - the electrical system functions as a gearbox with an arbitrary gear ratio. With the addition of power electronics the two shaft speeds can change independently, giving the effect of a variable ratio gearbox. This allows the shaft speed of the power turbine in the turbogenerator to be optimized without the usual constraints placed on fan shaft speeds by the fan tip speed limits. 
- Low power losses: Power loss is estimated to be $0.23 \%$ to $0.4 \%$ of the total power transmitted. This compares to $4 \%$ to $5 \%$ loss for a gearbox of comparable power.

- Minimal engine core jet noise: Designing to a low turbogenerator nozzle pressure ratio extracts the maximum amount of energy from the gas stream which has the effect of reducing the turbogenerator exhaust gas temperature and velocity and hence reduces noise. If turbogenerator noise remains too high for an exposed mounting location, the turbogenerator can readily be moved elsewhere on the aircraft without disturbing the fan nacelle location or operation.

- Only cold fan air in fan exhaust stream: The ability to physically separate the turbogenerator and its hot exhaust from the fan exhaust flow allows structures, such as blown flaps or pitch effectors, on which fan air impinges to be made with low temperature materials.

- Symmetric thrust in the event of a turbine engine or generator failure: All fan modules could continue operating at a reduced but symmetric thrust with the electric power from the remaining turbogenerator using a common electrical bus. Power inverters are required to allow the speed of the fans to be reduced to match the available power while the power and speed of the remaining turbogenerator are brought to a maximum.

- Asymmetric fan thrust for yaw control: The smaller span-wise distributed fans in this configuration have a rotational inertia that is much smaller than that of a single fan turbofan of comparable thrust. This low rotational inertia combined with the ability of electric motors to vary power almost instantly gives a much faster thrust modulation than that of an equivalent large single fan turbofan in which all rotating components change speed to change the thrust. In addition the turbogenerator operation can be kept constant by changing only the distribution of power across the individual fans such that the total power from the turbogenerator and the total thrust remain constant while providing yaw input to the vehicle. In addition the yaw input would be available from zero flight speed.

- Allows fan power to be produced by devices other than a turbine: Use of hydrogen or methane as a fuel and coolant could allow the electric power to be generated by a fuel cell in place of or in augmentation to the turbine driven generators. Also a fuel cell could use boil off from the cryogenic fuel tanks to provide ground and auxiliary electrical power without having to operate turbomachinery.

- Large electrical power off-take capability for in-flight and ground use. The turbogenerators could be oversized with regard to the power needs of propulsion to provide significant amounts of electrical power for nonpropulsion uses while in flight. The full generator capacity would be available for non-propulsion uses while on the ground.

- Concentrated power generation allows use of larger, more efficient turbomachinery: The larger turbomachinery in the two turbogenerators is more efficient than the smaller turbomachinery if the fans were replaced with discrete turbofan engines. Also physical size constraints on blade height are not reached until higher OPRs with larger compressors.

- Relatively inexpensive to design for multiple fan sizes: If it is advantageous or even mandatory to use more than one size fan for a given aircraft concept, only the fan and motor would have to be developed in multiple sizes, not the entirely different engines as would be the case for discrete engines of each size.

Furthermore, the following are identified as possible vehicle specific advantages for the currently proposed propulsion concept:

- Span-wise continuous fans give more BLI benefits: The continuous fan inlets take in all the boundary layer air and fill the wake across the entire span of the fan nacelle.

- "Accidental STOL": Inlets sized for cruise conditions experience considerable flow acceleration ahead of the inlet at low speed, high power flight conditions. This upper surface suction at take-off will delay flow separation and stall and thus increase the maximum lift coefficient. The effect is a by-product of the fan nacelle location and does not require any specific design features, hence the term accidental STOL.

- Very low community noise: Low pressure ratio fans exhausting across the top of the fuselage and well ahead of the trailing edge should have low source noise levels and very little downward propagation.

- Increased safety: Minimal engine rotor blade burst impact on passengers and vehicle structure due to the wing tip location of the turboelectric generators and the numerous low rotational energy fans mounted on the rear top side of the vehicle behind the rear pressure bulkhead. Also high density turbomachinery is located well away from the passenger spaces rather than immediately overhead as is the case with top mounted turbofans.

- Reduced lift-induced drag and wake vortex strength: The wing-tip location of the engine cores should help reduce both induced drag and tip vortex strength [17]. 
- The turbogenerator does not ingest boundary layer air: The fans can be located to reduce drag through BLI while the turbogenerators can be located where they can receive undisturbed, undistorted freestream air which yields highest pressure recovery and most stable and efficient turbomachinery operation.

- Lower fan nacelle structural weight: The inlet areas of the fan nacelle can be made lighter since they do on have to be designed to withstand the sudden internal pressure rise (hammer shock) resulting from a engine core stall.

- Greater pitch effector effectiveness: Blowing all the fan air over the pitch effector increases its effectiveness, allowing the pitch effector to be smaller and/or not located as far aft.

- Powered pitch control: The fan nozzle and pitch effector could pivot together to give powered pitch control that would be largely immune to being blanked by separation over the fuselage.

- Pitch effector can be made of low temperature tolerance material: Because only cold fan air impinges on it, the pitch effector does not have to be made of high temperature tolerant materials.

- Lower wing structure weight through better load distribution: The wing tip mounted turbogenerators and distributed span-wise fan installation gives wing-root bending moment relief and lower point loads. [18].

- Low cabin noise: The remote location of the turbogenerators and fans reduce sound intrusion into the passenger cabin area.

- Easier maintenance access: Access to the wing-tip mounted gas turbines and electric generators will be easier than embedded engine configuration.

However, using a distributed turboelectric propulsion system with superconducting devices may present adverse effects in overall vehicle performance and operation. The following are identified as possible drawbacks of the electrically driven system and of the newly proposed vehicle.

- Higher weight: The generators, motors, inverters, and the balance of the superconducting system may weigh more than a mechanical gearbox that accomplishes some of the same tasks as the turboelectric system.

- Possible non-linear aircraft control laws: Being embedded in the boundary layer may cause interactions between the external aerodynamics and the propulsion system.

- High system complexity: The superconducting electrical system adds to the complexity of the propulsion system.

- Operational difficulties: The superconducting system must operate in order for the plane to be able to fly. The superconducting parts and possible cryogenic fluids that must be operating correctly before the plane can be dispatched and must then continue to operate correctly once in flight. To be fair, a high power gearbox introduces its own set of operational complexities.

- Ice, snow, rain, etc. ingestion by the upper surface BLI 'mail-slot' inlet:

\section{Further Study and Research Directions}

As previously mentioned, the distributed electric propulsion concept is not limited only to hybrid-wing-body aircraft but also could easily be applied to other vehicle configurations such as traditional tube and wing aircraft and tilt rotor aircraft. Regardless of aircraft and engine configuration, embedded and distributed propulsion will require a greater emphasis on propulsion airframe integration through every step of the design process. In particular embedded inlets for which a substantial percentage of the inlet flow is boundary layer air must be analyzed in conjunction with airframe aerodynamic calculations to insure that inlet conditions are correctly calculated. A coordinated approach is required for all flight conditions and power levels since aircraft altitude, speed and angle of attack and side slip will affect boundary layer growth and thus inlet conditions. The converse is also true. Changing fan power changes the amount of air that can pass through the fan. This in turn affects the flow over the top surface of the wing-body immediately upstream of the fan inlet, which in turn affects the aircraft drag

The key to achieving all the benefits described in the sections above is the superconducting electrical system. Diligent R\&D effort in superconducting systems for aircraft application will be required to realize the potential of superconducting turboelectric propulsion. A large potential technology development payoff is in reducing the AC losses in HTS motors and generators. Those losses must be well below $1 \%$ in each machine to keep the required refrigeration reasonable. (Note that large generators already exceed $99 \%$ efficiency, even at room temperature.) The several types of AC losses that occur in HTS materials can be reduced by reducing the size of HTS filaments in the composite conductor and twisting them. An order of magnitude or more decrease in size from present practice is required. Such dimensions (and smaller) have been achieved in the older low-temperature superconductors, 
indicating promising approaches for the newer HTS materials. Further payoff should be available in cryogenic power inverter development.

In addition, the required refrigeration is proportional to the above losses, as is the required input power to drive the refrigerator and hence the refrigerator weight. Present cryogenic refrigerators of the required capacity have not been designed with low weight as an objective and must reach significantly lower weight per input power to be acceptable on aircraft. A factor of 3 to 6 reduction from the present best machines is desired. Improvements in refrigerator mechanical efficiency would also be effective but may be more difficult to achieve. As noted above, refrigeration would not be required on liquid-hydrogen-fueled aircraft or on ones carrying enough liquid hydrogen inventory to cool the electric components. Liquid methane should also be explored as a coolant/fuel. While not capable of eliminating the cryo-coolers entirely, liquid methane provides a low temperature sink that should greatly reduce the number of stages of cryo-cooling.

In order to determine an optimal fan pressure ratio and other propulsion system parameters, a more detailed understanding of inlet total pressure and velocity as well as the nozzle performance when exhausting over a horizontal surface is required. A detailed mission analysis is needed to optimize the fan propulsor modules and the turbogenerator as well as the combined propulsion system. The basic mission profile needs to be examined to determine the impact of cruise Mach number on mission fuel burn, block times and direct operating costs for different fuel prices. Other propulsor options, such as ducted-propeller systems, should be examined. The unique flexibility of the turbo-electric propulsion system is well suited to the examination of a wide range of propulsion and mission options.

\section{Concluding Remarks}

Current direct drive turbofans are reaching a lower limit on fan pressure ratio due to the low resulting fan shaft speeds and the effect of that low speed on the boost compressor and the fan turbine. To explore lower fan pressure ratios some type of gearbox is needed to allow the boost compressor and fan turbine to spin faster than the fan. However gearboxes in the 50,000+ horsepower range required for large twin engine transports drive gearbox technology to an extreme level.

This paper has examined the concept of using superconducting generators, motors and transmission lines as a means of transferring power from the turbines to the fan or fans. This power transmission method has the desired effect of allowing the power turbine to spin at any desired speed up to and possibly in excess of 10,000 rpm, while the fans spin at their best speed. Not only can the speeds of the turbine and fans be different, but the use of power inverters between the generators and the fan motors allows the speed ratio to change in flight giving the effect of a variable ratio gearbox. This is a capability not possible with mechanical gearboxes, and one which opens up a number of possible operational advantages such as maintaining symmetrical thrust if one turbogenerator goes offline, and allowing propulsion to play an active role in aircraft control by providing yaw input by changing thrust across the array of fans while keeping total power constant. The use of electrical power transmission allows a high degree of flexibility in positioning the turbogenerators and fan modules to best advantage. In the aircraft configuration examined the turbogenerators were located on the wing tips where the turbogenerator would see undisturbed freestream condition, while the fan modules were positioned in a continuous fan nacelle across the rear fuselage where they can ingest the boundary layer and thereby reduce the thrust required by the vehicle. Placement of the core and fans in a mechanical drive system is much more constrained.

An examination of the turboshaft and fan module thermodynamic performance for a range of fan pressure ratios was made with $\mathrm{N}+2$ and $\mathrm{N}+3$ technology level component efficiencies and temperatures. A minimum TSFC was observed to occur around an FPR of about 1.35 . The relatively high optimum fan pressure ratio is due to the relatively high pressure losses upstream of the inlet lip. A more in-depth analysis was made of the 1.35 FPR cycle. The total propulsion system was sized to meet the N2 vehicle thrust requirements at sea level, MN 0.25 , ISA +27 oR day of 108,000 lbf and at the aerodynamic design point of the vehicle of 31,000 ft, MN 0.8 of $27900 \mathrm{lbf}$ (after accounting for a $7 \%$ drag reduction due to boundary layer ingestion by the fans). The resulting propulsion system consists of 2 turbogenerators, each producing 53,900 shaft hp at the design point and 14 fans of 50 inch diameter driven by $7,700 \mathrm{hp}$ motors. The TSFC is 0.2781 at RTO design point and 0.4685 at the ADP.

During this analysis it became clear that using the standard approach to inlet performance calculation was not appropriate for the fan inlets for the configuration used. In turbofan engines where the inlet sees freestream conditions the ram drag is calculated as the inlet mass flow times the freestream velocity. However with inlets embedded in the upper surface at the trailing edge, the fan inlets do not see freestream conditions at all. About half of the 30 inch high inlet for the 1.35 FPR engine is boundary layer air, with the other half the inviscid air flowing over the top of the wing-body airfoil. For these configurations, we strongly urge the aircraft aerodynamicist and the 
propulsion analyst to work cooperatively during the very first stages of conceptual design to define the total pressure and velocity at the inlet physical lip. All processes upstream of the physical inlet lip would be the responsibility of the airframe, while all processes downstream would be the responsibility of the propulsion system. Because this is subsonic flow, changes in one regime effect the other and visa versa. Getting the inlet lip conditions correct is therefore an iterative process.

Superconducting generators and motors of the required power were analyzed and the size and weight estimated. The total loss in the superconducting devices may be as little as $0.03 \%$, if the current research into low loss $\mathrm{A} / \mathrm{C}$ stators bears fruit. This energy must be removed in order to maintain superconductivity. Several options for removing this energy were discussed. A system fueled entirely by jet fuel and with a cryo-cooler system exhausting to ambient is considered the baseline system. We estimate the weight of such an electrical system including motors and generators for the N3-X aircraft to be approximately 21,000 pounds. Cryogenic liquid hydrogen or liquid methane can be used first as a coolant and as a fuel. Liquid hydrogen can be used to cool the superconducting machinery directly eliminating the need for cryo-coolers. An all hydrogen fueled vehicle, however, would require tanks 4 times the volume required for jet fuel of equal total energy. The hydrogen flow rate to power the vehicle is considerably more than is required to cool the electrical system. At a $0.03 \%$ loss level in the superconducting elements and a $0.2 \%$ loss in the power inverter, a mixed hydrogen/jet fuel system is possible with just enough hydrogen flow to provide cooling. The hydrogen tank volume in a two fuel system would be about $40 \%$ of the volume of the jet fuel tanks. However, the hydrogen reduces the required jet fuel volume by $9 \%$. The net increase in total fuel tank volume is therefore $31 \%$ over an all jet fuel powered vehicle. A hybrid-wing-body presents a number of options for accommodating hydrogen tanks. Liquid methane can not be used to directly cool the superconductors, but it can provide a low temperature sink that would greatly reduce the size of the cryo-cooler system. It can directly cool the power inverters, further reducing the size of the cryo-cooler system. A total methane fuel aircraft would have a fuel tank volume $68 \%$ larger than required by jet fuel of equal total energy. Methane provides sufficient cooling capacity that a mixed methane/jet fuel system is also possible. A liquid methane tank sufficient to provide the required cooling would be about $34 \%$ the volume of the jet fuel tanks. However, the methane displaces about $17 \%$ of the jet fuel, so the total increase in fuel tank volume is only $17 \%$.

Superconducting turboelectric propulsion systems appear to be possible. Using electricity rather than mechanical means to transmit power between the turbine and fan does more than just allow the turbine and fan to spin at different speeds. It opens a wide range of configuration and operational possibilities. Further analysis in greater detail is required to fully quantify the advantage and disadvantages of this system in comparison to the other possible propulsion systems that may meet NASA's N+3 goals. 


\section{Appendix}

The following are plots of engine system performance for each of the different ADP Design fan pressure ratios examined.
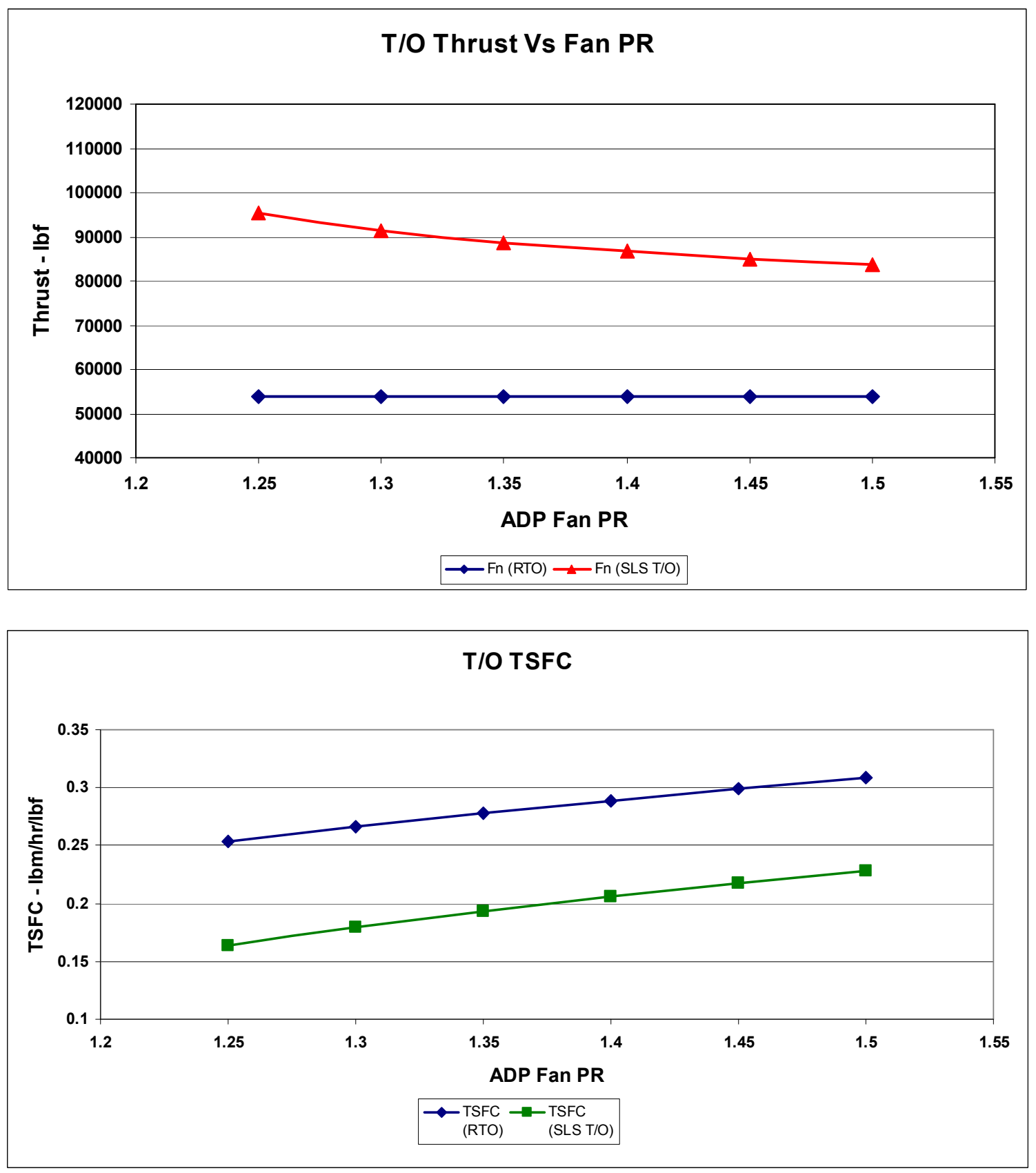

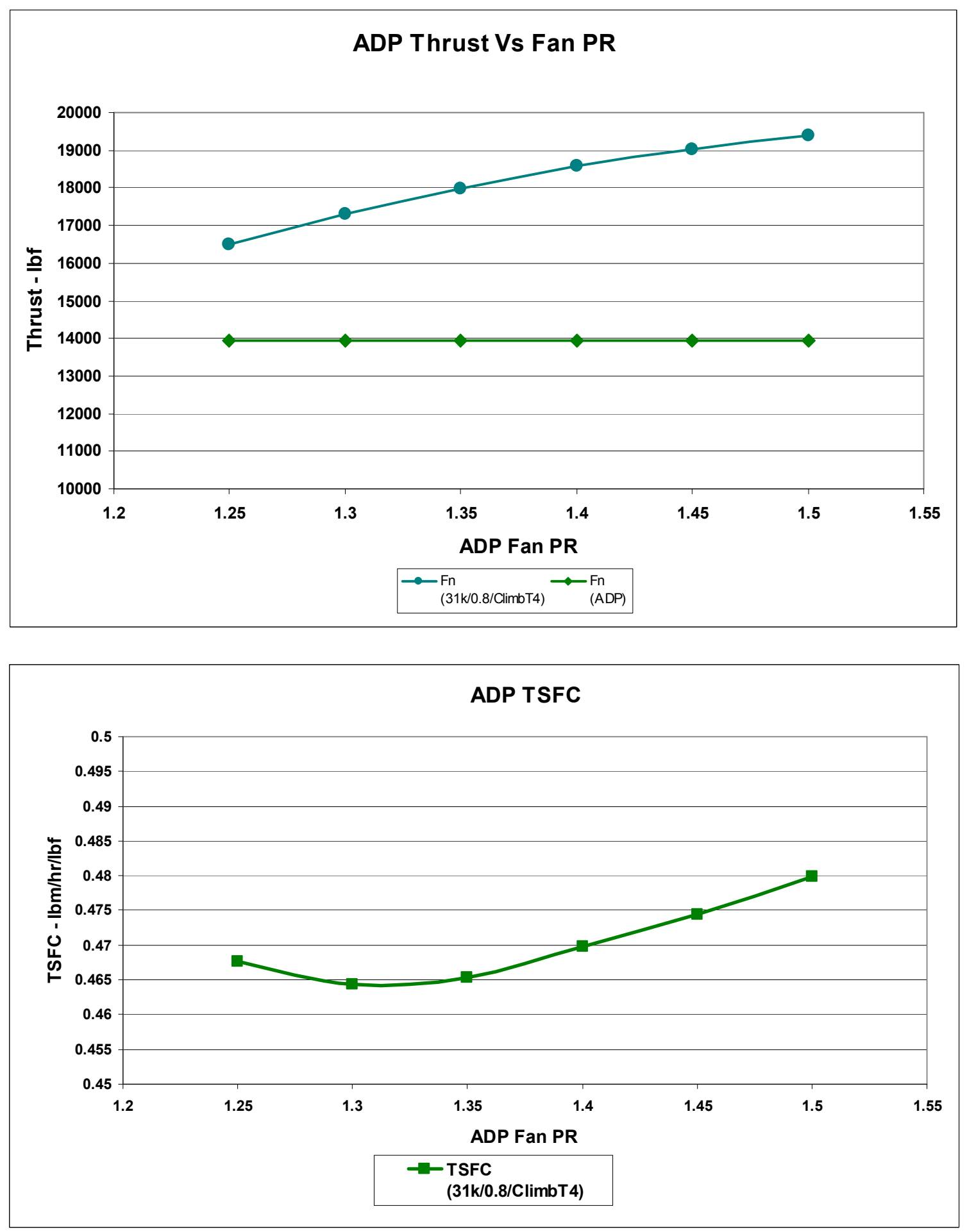

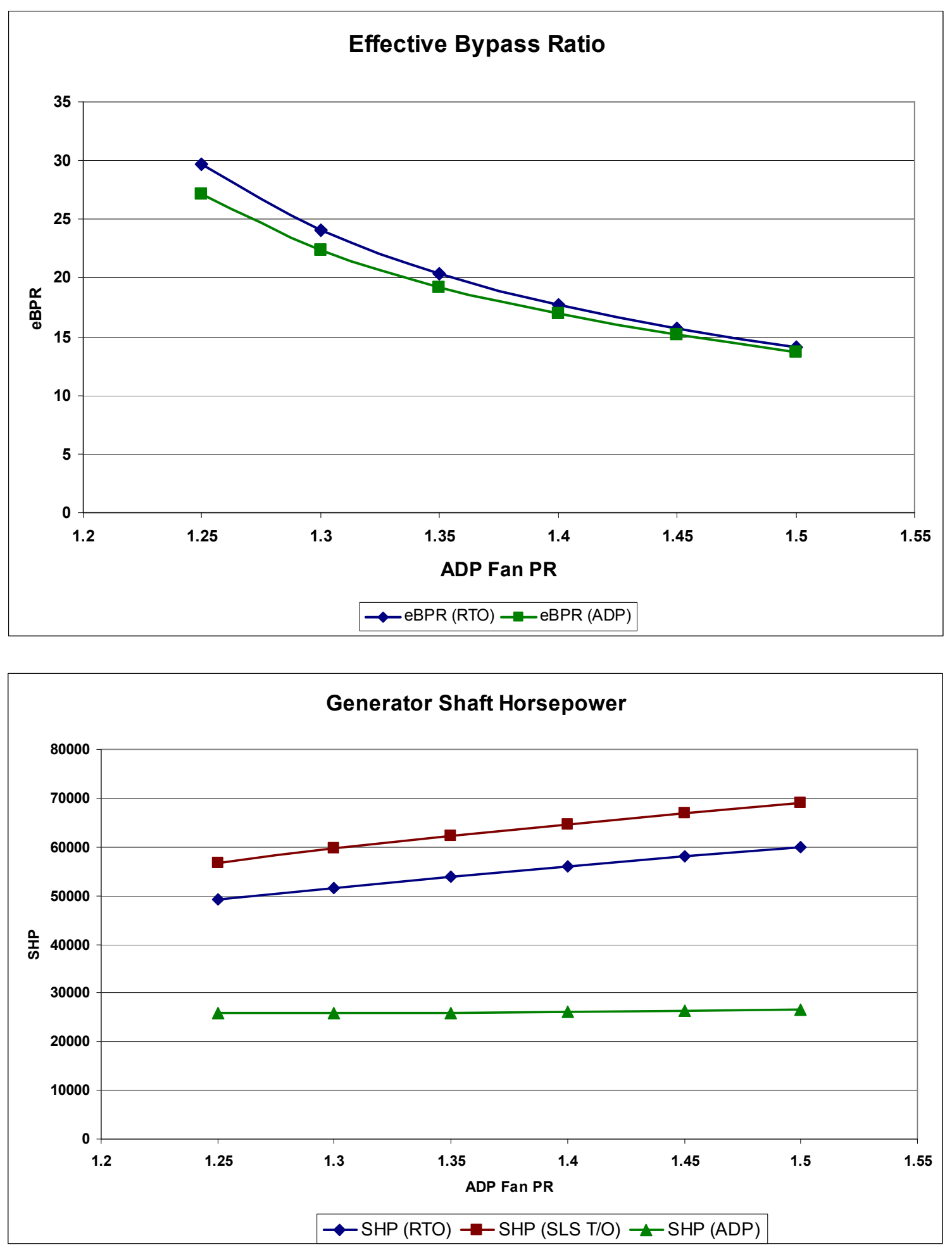

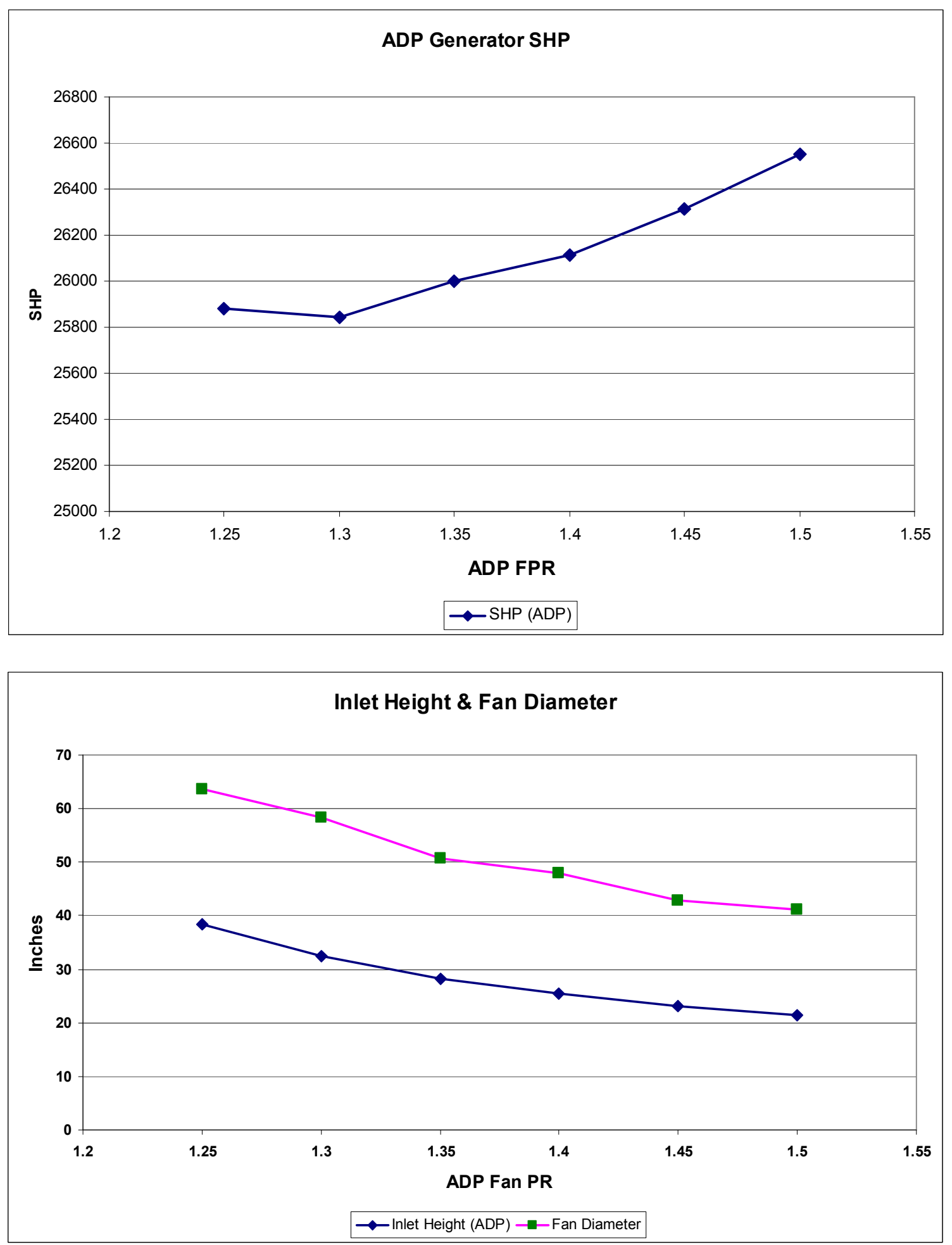

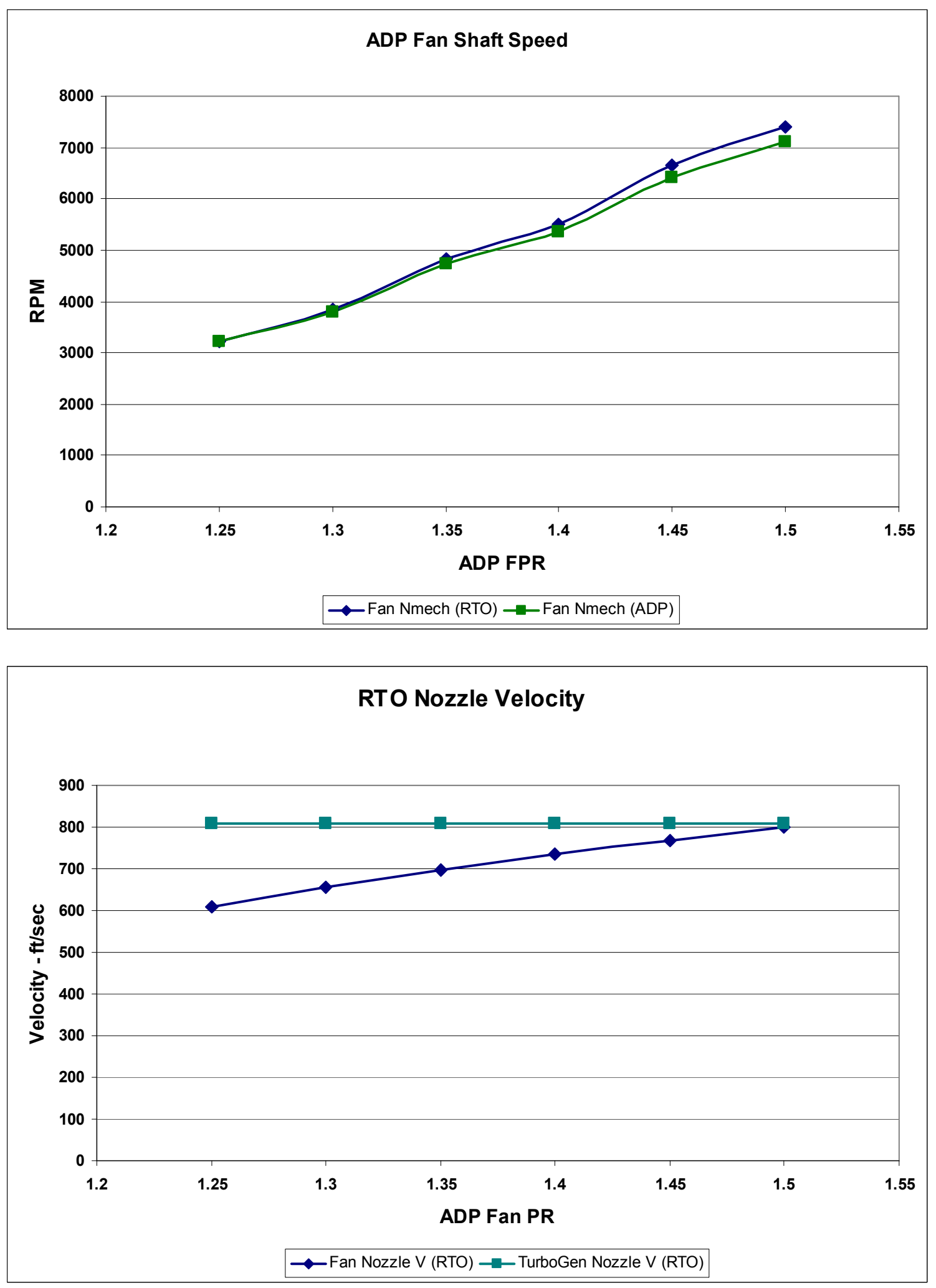


\section{References}

1. Kim, H.D., Berton, J.J., and Jones, S.M., "Low Noise Cruise Efficient Short Take-Off and Landing Transport Vehicle Study,” AIAA-2006-7738, Sep., 2006.

2. Stone, J.R., Krejsa, E.A., Berton, J.J. and Kim, H.D., "Initial Noise Assessment of an Embedded-Wing-Propulsion Concept Vehicle," AIAA-2006-4979, Jul., 2006.

3. Hileman, J.I, Spakovszky, Z.S., Drela, M., Sargeant, M.A., “Airframe Design for Silent Aircraft,” AIAA Paper 2007-453, Jan., 2007.

4. de la Rosa Blanca, E., Hall, C.A., Crichton, D., "Challenges in the Silent Aircraft Engine Design," AIAA Paper 2007-454, Jan., 2007.

5. Kim, H.D., Brown, G.V. and Felder, J.L., "Distributed Turboelectric Propulsion for Hybrid Wing Body Aircraft," 9th International Powered Lift Conference, London, United Kingdom, July 2008

6. Kawai, R, Brown, D, Roman, D, Olde, R, "Acoustic Prediction Methodology and Test Validation for an Efficient Low-noise Hybrid Wing Body Subsonic Transport", NASA Contract NNL07AA54C, Phase I Final Report PWDM08-006A, October, 2008.

7. Brown, G.V., Kascak, A. F., Ebihara, B., Johnson, D., Choi, B., Siebert, M., and Buccieri, C., "NASA Glenn Research Center Program in High Power Density Motors for Aeropropulsion," NASA/TM-2005-213800, 2005.

8. Kalsi, S.S, Weeber, K., Takesue, H., Lewis, C., Neumueller, H.W., and Blaugher, R.D., "Development Status of Rotating Machines Employing Superconducting Field Windings,” Proc. IEEE, vol. 92, no. 10, pp. 1688-1704, October 2004.

9. Barnes, P.N., Sumption, M.D., and Rhoads, G.L., "Review of High Power Density Superconducting Generators: Present State and Prospects for Incorporating YBCO Windings", Cryogenics, Volume 45, Issues 10-11, OctoberNovember 2005, Pages 670-686.

10. Oberly, C., "Lightweight Superconducting Generators for Mobile Military Platforms", Proceedings of the PES Meeting, June, 2006, Montreal, Quebec.

11. American Superconductor, URL: http://www.amsc.com/products/motorsgenerators/shipPropulsion.html [cited 31 December 2008]

12. Masson, P.J., Brown, G.V., Soban, D.S., and Luongo, C.A., "HTS Machines as Enabling Technology for AllElectric Airborne Vehicle," Supercond. Sci. Technol. 20, No.8, Aug. 2007, Pages 748-756.

13. Xi, H.X., Gong, W.Z., Zhang, Y., Bi, Y.F., Ding, H.K., Wen, H., Hou, B., Xin, Y., "China's 33.5 m, 35 kV/2 kA HTS AC Power Cable's Operation in Power Grid", Physica C, 445-448 (2006) 1054-1057.

14. Masson, Morega \& Tixador, "Preliminary Motor Design" draft, private communication, 2007.

15. Hughes, A. and Miller, T.J.E., "Analysis of Fields and Inductances in Air-Cored and Iron-Cored Synchronous Machines", Proc. of IEE, Vol 124, no 2, pp. 121-126,1977.

16. Miller, T.J.E. and Hughes, A., "Comparative Design and Performance Analysis of Air-cored and Iron-cored Synchronous Machines”, Proc. of IEE, Vol 124, no 2, pp. 127-132, 1977.

17. Bushnell, D. M., "Frontiers of the 'Responsibly Imaginable' in (Civilian) Aeronautics," AIAA Paper 98-0001, 1998.

18. Grasmeyer, J.M., et al., "Multidisciplinary Design Optimization of a Strut-Braced Wing Aircraft with Tip-Mounted Engines," MAD-98-01-01, Virginia Polytechnic Institute and State University, Jan. 1998.

19. 